Hugo Botha, MBChB

NiCole A. Finch, MS

Ralitza H. Gavrilova, MD

Mary M. Machulda, PhD

Julie A. Fields, PhD

Val J. Lowe, MD

Ronald C. Petersen, MD, $\mathrm{PhD}$

Clifford R. Jack, Jr., MD

Christina M. Dheel, BS

Debra J. Gearhart, AA

David S. Knopman, MD

Rosa Rademakers, PhD

Bradley F. Boeve, MD

Neurol Genet

2017;3:e201; doi: 10.1212

NXG.0000000000000201

\section{NOVEL GRN MUTATION PRESENTING AS AN \\ APHASIC DEMENTIA AND EVOLVING INTO \\ CORTICOBASAL SYNDROME \\ OPEN}

Mutations in the granulin $(G R N)$ gene on chromosome 17 most commonly result in behavioral variant frontotemporal dementia (FTD) or primary progressive aphasia (PPA), although a wide range of phenotypes have been described. ${ }^{1,2}$ At the time of publication, 172 mutations have been described (molgen.vib-ua.be/FTDMutations), 79 of which are thought to be pathogenic, with no clear genotypephenotype correlation. Here, we describe a novel mutation presenting as a dysexecutive, aphasic dementia and evolving into a corticobasal syndrome (CBS) phenotype.

Case report. A 61-year-old right-handed woman presented with difficulty expressing herself in writing more so than speech. Her problems started around the age of 60 , with deterioration of her penmanship. This was followed by difficulty with simple arithmetic, impairing her ability to work, as well as trouble with tasks reliant on sequencing, such as preparing a sandwich or making coffee. Closer to the time of evaluation, the patient and her family noticed word finding difficulty, yes-no confusion, word substitutions from semantically related categories, and mild gait imbalance.

Her initial cognitive evaluation revealed deficits in calculation and digit span, but no trouble with naming, recall, registration, or construction. Her repetition was spared, but she had difficulty following 3 step commands, and her writing was considerably impaired. She had clear left hemispheric atrophy and hypometabolism (figure 1A) and was amyloidPET negative. Formal neuropsychometric testing 18 months after symptom onset demonstrated impaired executive, letter/category fluency, and visuospatial skills (figure 1B). Over the following year, she developed more generalized cognitive, language, and motor impairment. She had right hemibody parkinsonism on examination and met the criteria for CBS during her second visit at age 62. ${ }^{3}$ At her last followup at age 63, she had minimal meaningful language output and little use of her right upper extremity, which was held in a flexed posture with marked
Clinical/Scientific Notes

rigidity. She had minimal behavioral disturbance and was still able to sing, despite being essentially nonverbal in conversation.

Her family history was notable for Parkinson disease and dementia (figure 2). Genetic testing was offered in light of the positive family history (Goldman score 2). ${ }^{4}$ Full sequencing of the GRN gene revealed a previously unreported mutation in exon 12 (c.1535delC, Pro512LeufsX5), resulting in a premature stop codon. Both MAPT sequencing and molecular analysis of the C9orf 72 gene were normal. Plasma progranulin levels were quantified and compared with subjects with known pathogenic mutations as well as controls (figure 1C). Controls had levels more than double that of known mutation carriers. The level in our case was far below than that seen in controls, albeit slightly higher than other known mutation carriers, supporting the pathogenicity of the mutation.

Discussion. It has been a little more than a decade since the first report linking mutations in the $G R N$ gene to cases of tau-negative familial FTD was presented. ${ }^{2,5}$ Despite important advances in our understanding of the role granulin plays in the nervous system, including as a growth factor and modulator of inflammation, the exact mechanism by which the haploinsufficiency that results from mutations causes neurodegeneration has not been elucidated.

Our case better illustrates the heterogeneity in $G R N$-related disease. Although related to a novel mutation in exon 12, a relatively rare site for $G R N$ mutations, her presentation shares features of previously reported mutations. Her initial complaint of deteriorating penmanship was likely due to apraxic agraphia, well reported in CBS, but reported only once in $G R N$-related CBS previously. ${ }^{6}$ Her phenotype at the time of initial evaluation did not qualify for a diagnosis of PPA based on her impairment in nonlanguage domains, but the prominent language difficulty is in keeping with PPA being the second most common presentation of $G R N$ mutations and a common early feature in CBS. ${ }^{1,7}$ Over time, a clear CBS picture emerged, another common manifestation of $G R N$ mutations. ${ }^{1,7}$ Her prominent parkinsonism, including marked rigidity, raises the possibility 

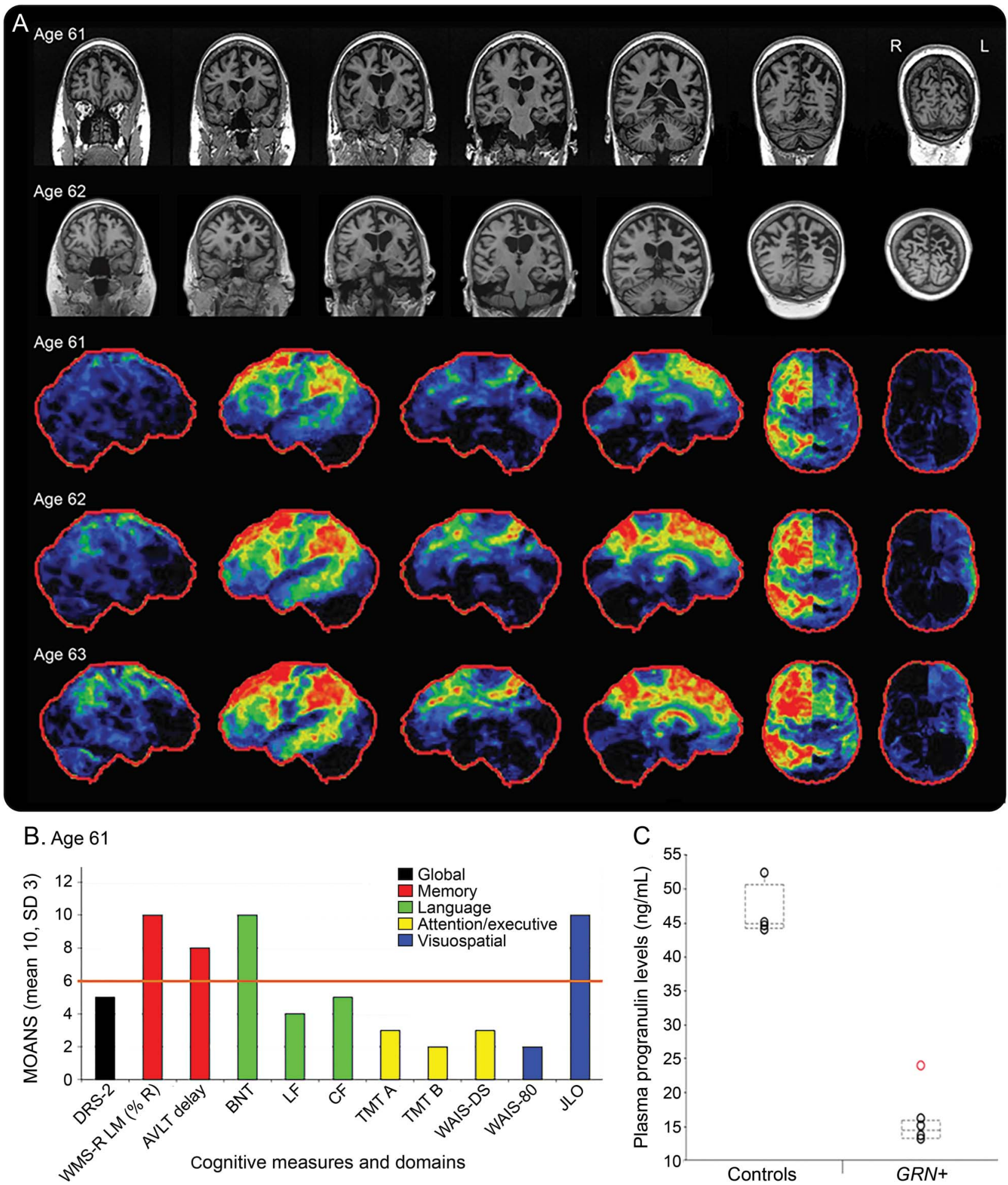

(A) MRI (rows 1 and 2) and FDG-PET (rows 3-5) findings at presentation (age 61 years) and follow-up (ages 62 and 63 years). Note moderate-to-severe, asymmetric left frontal-temporal-parietal atrophy, with progression at follow-up, and relative hippocampal sparing. The same pattern is present on fludeoxyglucose PET (FDG-PET) imaging, with almost exclusively left-sided hypometabolism even at follow-up, and little-to-no anterior and medial temporal involvement. (B) Performance on key tests in the neuropsychological battery is shown graphically, with performance on each test displayed using the Mayo Older American Normative Studies (MOANS) standard score as reference. Scores at or below 6 are usually considered abnormal. Impaired performance was found on fluency measures, attention/executing control measures, and one of the visuospatial measures. (C) Plasma progranulin levels quantified by ELISA in controls (CN) and affected mutation carriers (GRN+). Values in CN (mean $46.53 \mathrm{ng} / \mathrm{mL}$, SD $3.9 \mathrm{ng} / \mathrm{mL}$ ) were significantly higher than those in GRN + (mean $14.48 \mathrm{ng} / \mathrm{mL}, \mathrm{SD} 1.38 \mathrm{ng} / \mathrm{mL}$ ). The level in our case (23.9 ng/mL) is shown in red. AVLT $=$ Auditory Verbal Learning Test; BNT = Boston Naming Test; CF = category fluency; DRS-2 = Dementia Rating Scale 2; GRN $+=$ progranulin mutation cases; JLO = judgment of line orientation; $L=$ left; $L F=$ letter fluency; $R=$ right; TMT A = Trial Making Task Part A; TMT B = Trial Making Task Part B; WAIS-BD = Wechsler Adult Intelligence Scale Block Design; WAIS-DS = Wechsler Adult Intelligence Scale Digit Span; WMS-R LM = Wechsler Memory Scale-Revised Logical Memory. 
Figure 2 Outline of family pedigree

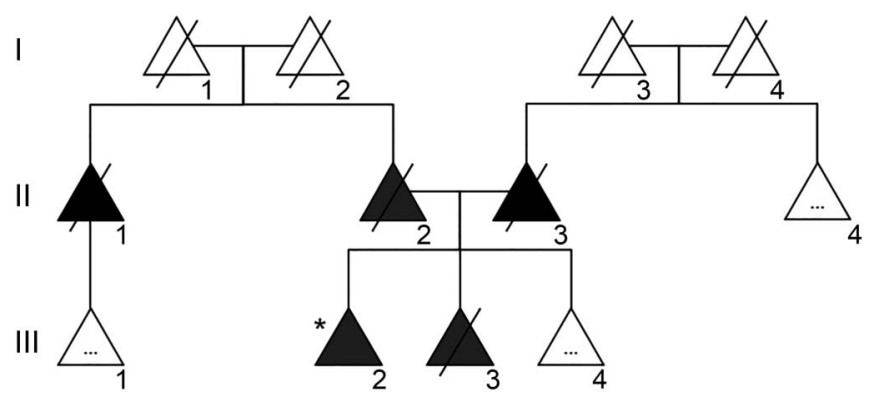

Triangles represent individuals, and shaded triangles represent individuals affected by a degenerative disease. Triangles with diagonal lines through them represent deceased individuals. The proband is indicated by an asterisk. An elipsis in a triangle represents multiple unaffected offspring not shown to maintain confidentiality. One parent was diagnosed with Parkinson disease (II.2) and the other with dementia (II.3), both late in life. A sibling of the parent with dementia was diagnosed with Alzheimer disease dementia late in life (II.1). One of the patient's siblings was suspected elsewhere to have Pick disease (III.3), based on behavioral disturbance, aphasia, and cognitive impairment, and this person passed away in the early 60 s. No postmortem examination was performed. Multiple other siblings were cognitively normal (all older than 45 years).

that the family member with parkinsonism may in fact have carried the same mutation. Although no imaging features are pathognomonic, $G R N$ mutations tend to cause more asymmetric atrophy and hypometabolism than is seen in sporadic FTD or in MAPT or C9orf72 mutations, as well as more parietal involvement and higher rates of atrophy. ${ }^{7-9}$ The reasons for the asymmetry, particularly marked in our case, remain a mystery, especially in light of the fact that the haploinsufficiency would be thought to affect both hemispheres to a similar degree.

Our case illustrates the importance of considering $G R N$ mutations in cases with markedly asymmetric involvement and a positive family history for dementia or parkinsonism.

From the Department of Neurology (H.B., R.C.P., D.S.K., B.F.B.), Department of Clinical Genomic and Neurology (R.H.G.), Department of Psychiatry and Psychology (M.A.M., J.A.F.), Department of Nuclear Medicine (V.J.W.), Department of Radiology (C.R.J.), and Alzheimer's Disease Research Center (C.M.D., D.J.G.), Mayo Clinic, Rochester, $M N$; and Department of Neuroscience (N.A.F., R.R.), Mayo Clinic, Jacksonville, FL.

Author contributions: Hugo Botha: acquisition of data, analysis and interpretation of data, and manuscript preparation. NiCole A. Finch and Ralitza H. Gavrilova: acquisition of data and analysis and interpretation of data. Mary M. Machulda and Julie A. Fields: acquisition of data. Val J. Lowe: acquisition of data, analysis and interpretation of data, and study supervision. Ronald C. Petersen: analysis and interpretation of data. Clifford R. Jack: analysis and interpretation of data and study supervision. Christina M. Dheel and Debra J. Gearhart: acquisition of data. David S. Knopman: acquisition of data and analysis and interpretation of data. Rosa Rademakers and Bradley F. Boeve: analysis and interpretation of data, study supervision, and critical revision of the manuscript for intellectual content.

Acknowledgment: The authors thank the patient and her family for participating in aging and dementia research.

Study funding: This study was funded by R35 NS097261, U01 AG045390, U54 NS092089, and P50 AG016574.
Disclosure: H. Botha and N.A. Finch report no disclosures. R.H. Gavrilova receives research support from the NIH. M.M. Machulda receives research support from the NIH and the Robert $H$. and Clarice Smith and Abigail Van Buren Alzheimer's Disease Research Program of the Mayo Foundation. J.A. Fields has received speaker honoraria from the American Academy of Clinical Neuropsychology; has served on the editorial board of the International Journal of Neuroscience; and receives research support from the NIH, the Robert H. and Clarice Smith and Abigail Van Buren Alzheimer's Disease Research Program of the Mayo Foundation, and the PatientCentered Outcomes Research Institute. V.J. Lowe has served on the scientific advisory boards of Piramal Imaging and Merck Research, Inc.; is a consultant for Bayer Schering Pharma, Merck Research, and Piramal Imaging Inc; and receives research support from GE Health care, Siemens Molecular Imaging, AVID Radiopharmaceuticals, the NIH (NIA, NCI), the Elsie, and Marvin Dekelboum Family Foundation, the Liston Family Foundation, and the MN Partnership for Biotechnology and Medical Genomics. R.C. Petersen serves on data monitoring committees for Pfizer Inc. and Janssen Alzheimer Immunotherapy; works as a consultant for Merck Inc, Roche Inc., Biogen Inc., Eli Lilly and Company, and Genentech Inc.; receives publishing royalties for Mild Cognitive Impairment (Oxford University Press, 2003); and receives research support from the NIH, the National Advisory Council on Aging (National Institute on Aging), and the Robert H. and Clarice Smith and Abigail Van Buren Alzheimer's Disease Research Program of the Mayo Foundation. C.R. Jack has provided consulting services for Eli Lilly; owns stock in Johnson and Johnson; and receives research funding from the NIH and the Alexander Family Alzheimer's Disease Research Professorship at Mayo Clinic. C.M. Dheel and D.J. Gearhart report no disclosures. D.S. Knopman receives research support from the $N I H$ and the Robert $H$. and Clarice Smith and Abigail Van Buren Alzheimer's Disease Research Program of the Mayo Foundation; has received speaker honoraria for lectures at the Behavioral Neurology Conference, $\mathrm{Hy}$ derabad, India, April 2016; served on the editorial board of Neurology; serves on Data Safety Monitoring Boards for Lundbeck Pharmaceuticals, the DIAN study, and the Consultant Bluefield project; and is an investigator in clinical trials sponsored by Biogen, TauRX Pharmaceuticals, Lilly Pharmaceuticals, and the Alzheimer's Disease Treatment and Research Institute, University of Southern California. R. Rademakers holds patents for Detecting and Treating Dementia, 12/302,691 (2008) and Methods and Materials for Detecting and Treating Dementia 12/413,869 (2009) and has received research support from $\mathrm{NIH}$, the Mayo Clinic Udall Center of Excellence, the ALS Therapy Alliance, the Consortium for Frontotemporal Dementia, and the Florida State Alzheimers Disease Research grant. B.F. Boeve has served as an investigator for clinical trials sponsored by GE Health care and Axovant; receives royalties from the publication of a book entitled Behavioral Neurology Of Dementia (Cambridge Medicine, 2009); serves on the scientific advisory board of the Tau Consortium; and receives research support from the NIH, the Robert H. and Clarice Smith and Abigail Van Buren Alzheimer's Disease Research Program of the Mayo Foundation, the Little Family Foundation, and the Mangurian Foundation. The Article Processing Charge was funded by the authors. Go to Neurology.org/ng for full disclosure forms.

This is an open access article distributed under the terms of the Creative Commons Attribution-NonCommercial-NoDerivatives $L i$ cense 4.0 (CC BY-NC-ND), which permits downloading and sharing the work provided it is properly cited. The work cannot be changed in any way or used commercially without permission from the journal.

Received August 10, 2017. Accepted in final form September 14, 2017.

Correspondence to Dr. Boeve: bboeve@mayo.edu

1. Yu CE, Bird TD, Bekris LM, et al. The spectrum of mutations in progranulin: a collaborative study screening 545 cases of neurodegeneration. Arch Neurol 2010;67: 161-170. 
2. Baker M, Mackenzie IR, Pickering-Brown SM, et al. Mutations in progranulin cause tau-negative frontotemporal dementia linked to chromosome 17. Nature 2006;442: 916-919.

3. Armstrong MJ, Litvan I, Lang AE, et al. Criteria for the diagnosis of corticobasal degeneration. Neurology 2013;80: 496-503.

4. Goldman JS, Farmer JM, Wood EM, et al. Comparison of family histories in FTLD subtypes and related tauopathies. Neurology 2005;65:1817-1819.

5. Gass J, Cannon A, Mackenzie IR, et al. Mutations in progranulin are a major cause of ubiquitin-positive frontotemporal lobar degeneration. Hum Mol Genet 2006;15: 2988-3001.
6. Passov V, Gavrilova RH, Strand E, Cerhan JH, Josephs KA. Sporadic corticobasal syndrome with progranulin mutation presenting as progressive apraxic agraphia. Arch Neurol 2011;68:376-380.

7. Le Ber I, Camuzat A, Hannequin D, et al. Phenotype variability in progranulin mutation carriers: a clinical, neuropsychological, imaging and genetic study. Brain 2008;131:732-746.

8. Rohrer JD, Ridgway GR, Modat M, et al. Distinct profiles of brain atrophy in frontotemporal lobar degeneration caused by progranulin and tau mutations. Neuroimage 2010;53:1070-1076.

9. Kelley BJ, Haidar W, Boeve BF, et al. Prominent phenotypic variability associated with mutations in Progranulin. Neurobiol Aging 2009;30:739-751. 


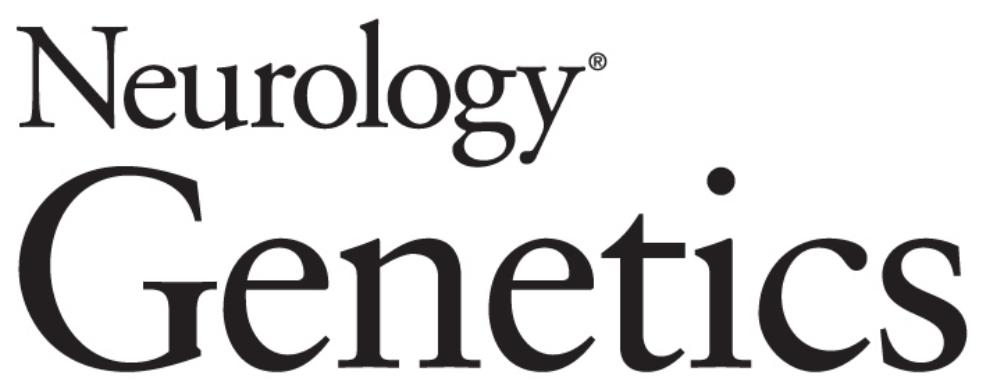

Novel GRN mutation presenting as an aphasic dementia and evolving into corticobasal syndrome

Hugo Botha, NiCole A. Finch, Ralitza H. Gavrilova, et al.

Neurol Genet 2017;3;

DOI 10.1212/NXG.0000000000000201

This information is current as of December 12, 2017

Neurol Genet is an official journal of the American Academy of Neurology. Published since April 2015, it is an open-access, online-only, continuous publication journal. Copyright Copyright ( 2017 The Author(s).

Published by Wolters Kluwer Health, Inc. on behalf of the American Academy of Neurology.. All rights reserved. Online ISSN: 2376-7839.

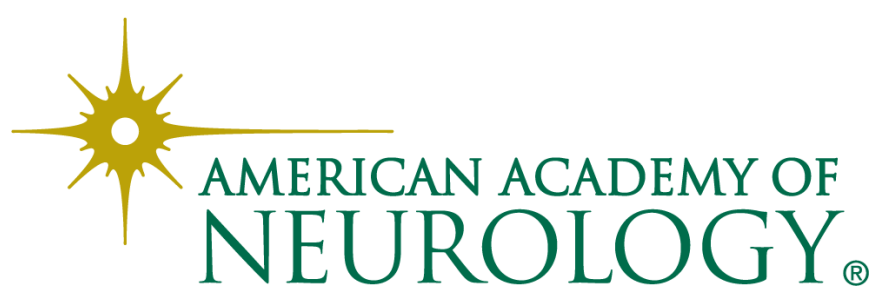




\section{Updated Information \& Services}

References

Subspecialty Collections

Permissions \& Licensing

\section{Reprints}

including high resolution figures, can be found at:

http://ng.neurology.org/content/3/6/e201.full.html

This article cites 9 articles, 0 of which you can access for free at: http://ng.neurology.org/content/3/6/e201.full.html\#\#ref-list-1

This article, along with others on similar topics, appears in the following collection(s):

\section{All Genetics}

http://ng.neurology.org//cgi/collection/all_genetics

Corticobasal degeneration

http://ng.neurology.org//cgi/collection/corticobasal_degeneration Dementia aphasia

http://ng.neurology.org//cgi/collection/dementia_aphasia

\section{Frontotemporal dementia}

http://ng.neurology.org//cgi/collection/frontotemporal_dementia

\section{PET}

http://ng.neurology.org//cgi/collection/pet

Information about reproducing this article in parts (figures,tables) or in its entirety can be found online at:

http://ng.neurology.org/misc/about.xhtml\#permissions

Information about ordering reprints can be found online:

http://ng.neurology.org/misc/addir.xhtml\#reprintsus

Neurol Genet is an official journal of the American Academy of Neurology. Published since April 2015, it is an open-access, online-only, continuous publication journal. Copyright Copyright $\odot 2017$ The Author(s). Published by Wolters Kluwer Health, Inc. on behalf of the American Academy of Neurology.. All rights reserved. Online ISSN: 2376-7839.

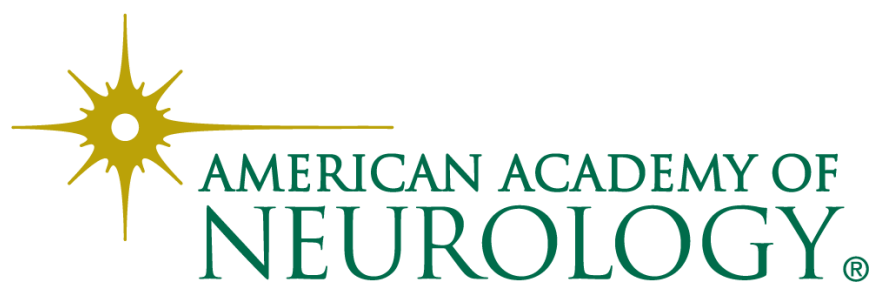

